\title{
CALEIDOSCÓPOLIS: SIGNOS DE CAMBIO EN LOS REPERTORIOS DE PROTESTA CALLEJERA EN LA CIUDAD DE CONCEPCIÓN - CHILE ${ }^{1}$
}

\author{
Caleidoscópolis: signs of change in the repertoires of street protest in Concepción - Chile
}

\author{
Rodrigo Ganter Solís* \\ Constansa Vergara Andrades** \\ Inti Fernando Fuica Rebolledo***
}

\begin{abstract}
RESUMEN
El trabajo constituye parte de un debate más amplio enmarcado en un Proyecto Anillo de Investigación sobre juventudes en el Chile contemporáneo y en un Proyecto Fondecyt sobre performatividad y construcción social de lo corporal en jóvenes urbanos. Los datos que aquí se presentan incluyen los años 2011 a 2016, en la ciudad de Concepción-Chile. Su objetivo general fue estudiar los principales cambios en los repertorios de protesta callejera en el contexto del movimiento estudiantil chileno, explorando las relaciones entre política, estética, cuerpo, espacio urbano y emociones colectivas, al interior de lo que aquí denominamos artivismo urbano juvenil, en tanto proceso de subjetivación política de
\end{abstract}

\footnotetext{
${ }^{1}$ El presente artículo forma parte del Proyecto Fondecyt de Iniciación No 11140866, del cual el autor principal del artículo es el investigador responsable; y que se titula: "Prácticas y Sentidos de lo Corporal en Jóvenes Urbanos de Concepción y Santiago", financiado por el Fondo Nacional de Desarrollo Científico y Tecnológico (Chile) y patrocinado por la Universidad de Concepción en el marco de la pasantía postdoctoral que el autor realizara en la Facultad de Historia y Geografía de la Universidad de Barcelona durante el segundo semestre del año 2016.
}

* Departamento de Sociología, Facultad de Ciencias Sociales, Universidad de Concepción. Concepción, Chile. Correo electrónico: rganter@udec.cl

** Investigadora Asistente del Proyecto Conicyt Anillo Juventudes SOC-1108. Correo electrónico: constansavergara@gmail.com

*** Investigador Asistente del Proyecto Conicyt Anillo Juventudes SOC-1108. Correo electrónico: inti.fuica.rebolledo@gmail.com

Artículo recibido el 06 de agosto de 2015. Aceptado el 24 de abril de 2017. 
nuevo tipo. La investigación tuvo un carácter etnográfico e implicó la aplicación de una batería de técnicas que combinan el relato etnográfico, las entrevistas en profundidad, la producción de imágenes fotográficas y el mapeo colectivo con activistas del movimiento en la ciudad de Concepción. El texto discute los principales impactos de las tácticas de desobediencia civil en este contexto, su alcance en el desenlace del movimiento y en la propia reconfiguración del horizonte político en el Chile tardo-pinochetista.

Palabras clave: subjetividad política, espacio urbano, cuerpo, emociones, conflicto social.

\begin{abstract}
The work is part of a broader debate framed in a Ring Project of research on youth in contemporary Chile and a Fondecyt Project on performativity and social construction of the body in urban youth. The data presented here includes the years 2011 to 2016, in the city of Concepción-Chile. Its general objective was to study the main changes in street protest repertoires in the context of the Chilean student movement, exploring the relationships between politics, aesthetics, body, urban space and collective emotions, within what we call here urban youth artivism, in so much process of political subjectivation of new type. The research had an ethnographic character and involved the application of a battery of techniques that combine the ethnographic story, the in-depth interviews, the production of photographic images and the collective mapping with activists of the movement in the city of Concepción. The text discusses the main impacts of civil disobedience tactics in this context, its scope in the outcome of the movement and in the actual reconfiguration of the political horizon in late Pinochet-Chile.
\end{abstract}

Keywords: Political subjectivity, urban space, body, emotions, social conflict.

\title{
CONTEXTO Y ANTECEDENTES DEL ESTUDIO
}

\section{"Si no nos dejan soñar, no los dejaremos dormir". E. Galeano}

El año 2011 de algún modo será recordado por la explosión global y coreográfica de diversas movilizaciones ciudadanas y revueltas urbanas que impugnaron los modos mediante los cuales las diversas estructuras de poder gestionan arbitrariamente la vida de las personas y coartan la posibilidad de participar genuinamente en la toma de decisiones. Lo anterior se suma a un rechazo colectivo frente a los sistemas políticos imperantes y un importante descontento ciudadano derivado de la existencia de profundas brechas de desigualdad social. Las demandas, los lugares, los actores, las formas de manifestación fueron múltiples e incluyeron a Chile, México, España, Nueva York, Siria, Yemen, Colombia; y más 
tarde Turquía, Brasil, etc. En general, se puede plantear que dichos movimientos de protesta han evidenciado una fuerte y transversal presencia generacional en su composición interna. Por ejemplo, para el caso de Egipto, se hablará durante el año 2011 de la "revolución de los jóvenes", y que precisamente fuera esta la que pusiera fin al régimen de Mubarak (Toussaint, 2012). Lo que decantó en que autores como Wallerstein (2012) acuñaran la idea de una geografía de la protesta social a nivel global, lo que define muy bien el clima social que predominó durante dicho año.

En nuestro caso, durante diciembre del año 1989, Chile tuvo su primera elección presidencial después de 19 años sin presidente electo democráticamente; allí obtiene el triunfo el bloque político de la Concertación de Partidos por la Democracia. Sin embargo, poco antes de que la Concertación asumiera el mando, Pinochet decreta la Ley Orgánica Constitucional de Educación (LOCE). Durante mayo del año 2006 se inicia, después de muchos años, un nuevo ciclo nacional de movilizaciones estudiantiles, esta vez en contra del modelo educacional, su diseño, funcionamiento y organización. Lo central de la discusión estuvo puesto en la LOCE, donde no se garantizaba el rol del Estado en materia educativa, ni tampoco la calidad de la enseńanza, agudizando con ello las brechas de desigualdad y la segregación socio-educativa entre distintos tipos de establecimientos educacionales. Las movilizaciones del año 2006 desplegaron una singular creatividad y capacidad organizativa de los y las estudiantes. A ello se sumó su composición transversal que incluyó a amplios y diversos sectores tanto políticos como de naturaleza más expresiva y cultural. Lo que interpretó a la ciudadanía en general, consolidando una película de unidad y ensamble interno que abarcó desde colectivos, federaciones, hasta instancias de base más territorial y descentralizada. A nuestro juicio toda una ruptura generacional ${ }^{2}$ que sedimentó las bases y los aprendizajes para la configuración del acontecimiento del año 2011. Este movimiento fue conocido como la Revolución Pingüina del año 2006, logrando situar la crisis del modelo educacional chileno (como signo de una crisis más profunda en el patrón de acumulación tardo-capitalista) en un lugar prioritario de la agenda nacional. Durante

\footnotetext{
${ }^{2}$ Seguimos en este punto las contribuciones de Margaret Mead (2009), Karl Mannheim (2005), Carles Feixa (2012) y Víctor Muñoz (2012); Yanko González (2010), en el entendido que el vínculo generacional surge a partir de la irrupción de acontecimientos que rompen con una cierta inercia y estabilidad socio-histórica de una sociedad y al mismo tiempo dichos acontecimientos generan marcas importantes en la memoria social de los miembros de un grupo de edad joven o inserto dentro de un momento de formación para la vida social. En ese mismo plano, las unidades generacionales re-interpretan y significan con mayor fuerza vivencias que pueden ser problemáticas o traumáticas, según su propia adscripción social. Desde esta perspectiva -que no vamos a desarrollar aquí- el nuevo contingente juvenil porta el germen de una nueva generación capaz de dinamizar lo social, dada su particular disposición al cambio social y su inicial integración material y simbólica al orden social imperante.
} 
el año 2010 el escenario social y político estuvo marcado por la instauración de la derecha en el gobierno y por el suceso del terremoto del 27/F. Y tras la aprobación del proyecto Hidro-Aysén en el mes de mayo del año 2011, la ciudadanía decidió salir a la calle y protestar en diversas ciudades de Chile, dando paso a la primera marcha masiva de ese año (10/05/2011), que congregó a distintos sectores sociales para rechazar la iniciativa del gobierno. Ese día marcó un precedente para lo que vendría después, ya que los estudiantes convocaron a una jornada de paro y protesta nacional para el día 12 de mayo. Las demandas se centraban nuevamente en la educación, poniendo como foco: el fin al lucro, la gratuidad universal en materia educativa, la calidad de sus procesos y la recuperación de la educación pública en Chile. A partir de esa coyuntura las convocatorias del movimiento estudiantil a marchar y a ocupar los espacios públicos de las principales ciudades de Chile se realizaron semanalmente durante el año 2011, y de modo más intermitente entre los años 2012 a 2016. Distintos autores plantean que estas movilizaciones son el resultado de una crisis de desconfianza profunda en las instituciones básicas de nuestra sociedad; de la evidente relación incestuosa entre dinero y política; y de un creciente malestar colectivo con el modelo económico y con el sistema político (Ruiz, 2013; Mayol, 2012; Segovia y Gamboa, 2012; Garcés, 2012; Fernández, 2013). Asimismo, en este escenario se vienen observando potentes movimientos territoriales de carácter regionalista, muchos de estos avanzan desde las cuestiones reivindicativas a las demandas por la autonomía y el derecho a una ciudad más justa (Valenzuela y Basaure, 2016).

Nos interesa plantear una transformación inicial y preliminar-que hemos ido observando etnográficamente- en los repertorios de acción colectiva callejera que estos jóvenes vienen utilizando en contexto de protesta y movilización social, particularmente a partir del escenario abierto por los episodios del año 2011 y que aquí abordaremos como artivismo urbano juvenil. Proponemos no una consolidación, sino una dinámica social en proceso de configuración y que entra a recombinarse con formas tradicionales de manifestación social en el espacio público utilizada por los actuales movimientos sociales (Tarrow, 2004; Melucci, 1996; Mouffe, 1999; Zibechi, 2003; Garcés, 2012). Asociado con lo anterior, nos interesa avanzar en las relaciones entre este tipo de manifestaciones colectivas y el factor de combustión que actualmente juega tanto la dimensión espacial como el componente socio-emocional en la protesta callejera, donde lo corporal, la calle, la política y la estética se ensamblan (Le Breton, 2011; Traugott, 2002, Reguillo, 2005; Urteaga, 2011; Scribano y Boito, 2012; Botero, 2011; Bonvillani, 2013; Aimar, 2012; Fernández, 2007; Ganter y Zarzuri, 2005) para producir nuevas geografías itinerantes del desacato y la desobediencia civil ${ }^{3}$, que trasforman súbita

\footnotetext{
${ }^{3}$ Asumimos la perspectiva de Hannah Arendt (1999) sobre este concepto. En el cual se expresa la
} 
y fugazmente a la ciudad en un mosaico móvil de experiencias colectivas. Lo que aquí llamamos efecto Caleidoscópolis ${ }^{4}$.

Ahora, aun cuando no sea posible hablar de una única juventud, sino de juventudes con rasgos muy heterogéneos y desiguales, se hace posible identificar a esta generación que participó en este movimiento estudiantil como una generación de estudiantes mucho más preparada y educada que sus padres. En general son hijos de una muy variada y fragmentada clase media, que incluye un alto porcentaje de familias sobre-endeudadas y altamente precarizadas laboralmente. Herencia de la aplicación extrema del neoliberalismo en Chile, donde el equilibrio de las economías familiares y la integración social se vuelven inestables como regla (Ruiz, 2013; Mayol, 2012). Son jóvenes altamente organizados, pero prefieren las dinámicas de organización y participación menos jerárquicas y verticales. Prefieren las redes sociales a las orgánicas rígidas. Nacieron cuando internet ya estaba operando en nuestro país, por lo que poseen una fuerte empatía con la cultura visual y las nuevas tecnologías de la comunicación. Suelen ser más incrédulos que la generación de sus padres y desconfían fuertemente de las instituciones sociales tradicionales. Son más pragmáticos que idealistas, y como crecieron en un mundo mucho más complejo y diverso que sus padres, son mucho más respetuosos de la diferencia en todas sus formas. Prefieren la acción directa para conseguir sus objetivos que ser mediados por instancias ajenas a su vida cotidiana, de modo que suelen ser más impacientes y desean resultados inmediatos. Poseen una sensibilidad por las grandes causas: ecología, derechos humanos, diversidad sexual, desigualdad social, la democracia, la soberanía alimentaria, etc. (Sandoval, 2015). Paradójicamente han tenido más acceso a la educación que sus padres, pero menos oportunidades de obtener un empleo de calidad. Más acceso a la información, pero menos oportunidades y espacios de participación para incidir en la toma de decisiones. Más autonomía personal e individual, pero menos cobertura para ejercerla y vivirla como ellos quisieran (Hopenhayn, 2004).

participación democrática directa de los ciudadanos, toda vez que no son escuchados o los canales de cambio institucional no funcionan. De modo que se van constituyendo embriones para la reorganización futura del sistema político oficial.

${ }^{4}$ Noción construida por los autores del presente artículo y que combina la palabra "caleidoscopio" con "polis". Ambas palabras vienen del griego; etimológicamente caleidoscopio refiere a: kálos = bello; eidos = imagen; skopein = ver; o sea, ver imágenes bellas. $Y \pi$ ó $\lambda ı \varsigma$ = polis, que refiere ciudad. Así nos queda: ver imágenes bellas en la ciudad o ciudad donde se ven imágenes bellas. 


\section{CONDICIÓN(ES) JUVENIL(ES): POLÍTICAS DE LA CALLEY ELAFECTO}

Podemos considerar que "la juventud es la forma en que una sociedad determinada organiza esta etapa del desarrollo en el proceso de vida social de los sujetos, por lo que se le cataloga como un grupo con características diferentes a las de otros grupos sociales, como lo podrían ser el de los adultos, los ancianos y los niños” (Nateras, 2004, p. 207). Es relevante aquí hablar de juventudes, antes que de una única juventud, pues así podemos reconocer las diferencias y complejidades internas existentes dentro del entramado social propio de los y las jóvenes, reconociendo las divergencias y posibilitando diferenciar las miradas sobre lo juvenil. A partir de los años 90, se observa como las juventudes comienzan a estructurarse de forma particular, en directa relación con el proceso denominado como globalización y el avance de nuevas tecnologías de la información que cambian profundamente los modos y tiempos de comunicación, proceso en el cual los y las jóvenes conocen de primera mano y pertenece a su terreno histórico-social propio (Reguillo, 2000; Ganter, 2015; Juris, Pereira y Feixa, 2012; Aguilera, 2014). En términos políticos, esto ha repercutido ampliamente en una reconsideración de $l o$ político, con un alto descrédito de los canales institucionales de participación y una alta valoración de formas emergentes de organización contingente (Feixa, 2006; Zarzuri y Ganter, 2002; Nateras, 2004; Urteaga, 2011; Reguillo, 2000; Muñoz, 2011; Aguilera, 2014). A través de vinculación por redes, los jóvenes se organizan en protestas marcadas como actos culturales, con una alta preocupación por problemáticas globales, a la vez que reivindicaciones a nivel local (Nateras, 2004; Juris, Pereira y Feixa, 2012). A pesar de compartir un contexto socio-histórico que dota a los y las jóvenes de un marco de socialización general compartido, en la práctica las condiciones materiales de estos/as no son homogéneas, ni se ven todos/as enfrentados a las mismas dificultades, ni poseen el mismo horizonte de desarrollo. Reguillo (2010 en ODJ, s.f.) propone respecto de la condición juvenil contemporánea dos tipos base de juventudes: en primer lugar una juventud precarizada, con bajos vínculos institucionales, bajos ingresos y baja seguridad, y en segundo lugar una juventud conectada, incorporada a la institucionalidad, con mayores posibilidades de desarrollo, a los que podríamos sumar una tercera, marcada por el esfuerzo. Aquellos jóvenes que se mantienen ligados al sistema a través de un esfuerzo enorme y con costos de precarización de sus condiciones de vida importantes: estudiantes que trabajan, trabajadores sin seguridad laboral, y cuya condición juvenil tiene una diversidad enorme de anclajes (Reguillo citado en Seoane, 2007). La multiplicidad de territorios en torno a los cuales los y las jóvenes van configurándose como tales tiene una fuerte expresión en una alta emergencia de prácticas divergentes, de espacios colectivos de participación acotados y que se diferencian ampliamente de aquellas grandes utopías movilizadoras de décadas 
anteriores (Reguillo, 2000; Nateras, 2004; Reguillo en Seoane, 2007; Ganter y Zarzuri, 2005). De esta multiplicidad de adscripciones, en donde un joven puede participar de distintas orgánicas que entre sí no tienen por qué poseer una relación, es que "ya no es posible comprender las identidades de modo unívoco y lineal a partir de sus manifestaciones" (Krauskopf, 2010, p. 33). Las identidades juveniles no son situacionales y transitorias, sino que multicéntricas, contienen en sí una amalgama de adscripciones que permite la construcción de vínculos múltiples, con la posibilidad de que sean estos independientes entre sí (Urteaga, 2011).

En retrospectiva, podemos caracterizar -en general- a los jóvenes de los años 60 y 70 como altamente motivados por la política como motor de cambio social, sobre todo en un contexto radicalizado por la "guerra fría" y el predominio de visiones ideológicas. Donde además la política era una política de partidos de masas y doctrinarios, donde la militancia tendía a hacerse abstracta y subordinada a una disciplina de cuadros, orientada por un mandato moral y sacrificial, inscrito al interior en un proyecto de nación, una cruzada. Mientras que para los jóvenes del siglo XXI la militancia - por lo menos tradicional- tiende a desdibujarse y perder legitimidad velozmente (Balardini, 2005; Salazar, 2002), lo que no significa que desaparezca o surjan otros modos de concebirla generacionalmente (Muñoz, 2012), más bien lo que va surgiendo es un tipo de participación juvenil que ensambla lo ético con lo estético, la razón con la emoción, lo que en la práctica ha decantado en una política caleidoscópica que tensiona el sistema político tradicional, potenciando la ya desatada crisis de representatividad al interior del mismo (Reguillo, 2000; Zarzuri y Ganter, 2002; Balardini, 2005; Urteaga, 2011; Botero y Muñoz, 2011). Leslie Serna (1998) ya venía caracterizando para el caso mexicano la experiencia de movilizaciones novedosas; la acción directa e inmediata en la búsqueda de soluciones concretas para situaciones que los perjudican; la revaloración de la autonomía y la posición de la individualidad al interior de la organización; el énfasis en la horizontalidad en la toma de decisiones y su estructuración en red (Serna, 1998; Balardini, 2005; Ganter y Zarzuri, 2005). Estas formas de hacer política -sobre todo las que observamos en Chile desde el hito del año 2011- también se han caracterizado por despegar un componente eminentemente espacial, imprimiéndole a las ciudades un clima de disputa territorial permanente, mezclado con signos multicolores de fiesta irreverente, donde se conjuga la protesta callejera en el espacio público con las dinámicas creativas de carnaval urbano (Urteaga, 2011; Reguillo, 2005; Aimar, 2012; Opazo, 2009; Fernández, 2013; Natanson, 2013).

Desde la normalización institucional de la democracia en Chile, los repertorios de la acción colectiva en contexto de protesta y movilización urbana vienen mostrando importantes signos de cambio; pues no solo es posible evidenciar un relevo del "sujeto histórico" que se viene desplegando en las calles de nuestras grandes ciudades (ya que este último parece estar diversificado en demanda y 
fisonomía), sino que los propios repertorios clásicos de protesta -como la marcha, la barricada, la ocupación de infraestructuras, el corte de rutas, los lienzos y los cánticos- han sido permeados virulentamente por acciones de tipo estéticas o de corte festivo (Aimar, 2012; Fernández, 2013; Botero y Muñoz, 2011; Bonvillani, 2013; Urteaga, 2011; Delgado, 2013); donde se incluye fuertemente al cuerpo como soporte expresivo de la denuncia y a la música o la dramaturgia para intensificar en la multitud de activistas un clima socio-emocional (Scribano, 2012; Bonvillani, 2013; Aimar; 2012; Traugott, 2002) que ensambla poderosamente lo lúdico y lo político en el marco de la ocupación de la calle, como lo pudimos observar en Chile durante el año 2011. De este modo, entenderemos al artivismo (Delgado, 2013) como la combinación de prácticas de protesta política con acciones de arte, despegadas en el espacio público durante las movilizaciones organizadas por el movimiento estudiantil del año 2011 y siguientes en las principales ciudades de Chile. Sus protagonistas: jóvenes estudiantes secundarios y universitarios.

Por otro lado, la investigación de la dimensión espacial de la protesta (Auyero, 2002; Oslender, 2002; Lefebvre, 2013; Massey, 1994; Soja, 1989) aun es escasa en nuestras sociedades (Auyero, 2002; Oslender, 2002;), y eventualmente cuando se materializa ese desafío lo que se observa en la literatura es un análisis predominantemente conceptual, donde la representación cartográfica y visual aún son insuficientes. Planteamos que la protesta no solo tiene lugar en el espacio urbano en tanto escenografía, sino que los propios activistas se apropian del espacio, lo recuperan en su beneficio (Pile, 1997), le otorgan sentido, lo cargan simbólicamente con sus experiencias y sus múltiples formas de uso divergente o intersticial (Scribano, Magallanes y Boito, 2012). Precisamente en situaciones en que los activistas y manifestantes logran colonizar un espacio público, lo recuperan del control de las fuerzas policiales o irrumpe una acción colectiva performativa, se configura automáticamente un clima socio-emocional que potencia la euforia en el espacio, la alegría multitudinaria, los sentidos compartidos y la pertenencia a un universo mayor de relaciones sociales. La protesta urbana deviene en fiesta (Aimar, 2012) y el recuerdo personal en memoria colectiva viva. De ahí la relevancia del componente socio-emocional de los movimientos sociales y de las diversas formas de ocupación de la ciudad en contexto de protesta urbana (Melucci, 1996; Scribano, 2012; Aimar, 2012; Bonvillani, 2013; Mouffe, 2005; Traugott, 2002).

Para autores como Oslender (2002), el concepto de espacio es preferentemente político (Lefebvre, 2013, Borja y Muxí, 2003; Salcedo, 2002) y estratégico (Massey, 1994) constreñido por una red compleja de relaciones de poder/saber, pero nunca exento de usos divergentes, tácticas oblicuas, resistencias o insurgencias (Foucault, 1992; Arditi, 2012; Salcedo, 2002), todas susceptibles de mapear o cartografiar de modo participativo, particularmente en contextos de movilización urbana como los ocurridos durante año 2011 en Chile. 


\section{DISEÑO METODOLÓGICO}

El trabajo se aborda desde un enfoque metodológico etnográfico (Guber, 2001). Lo que implicó un trabajo de campo colaborativo y colectivo iniciado en mayo del año 2011 hasta junio del año 2016 en la ciudad de Concepción. En este contexto, privilegiamos lo que se entiende por etnografía de eventos (Borges, 2003; Bonvillani, 2013), donde observamos y participamos en un conjunto de manifestaciones y convocatorias a protestas estudiantiles en el marco del movimiento estudiantil. Lo que supuso la implementación de diversas técnicas de investigación como la observación participante: durante las manifestaciones callejeras; después de las manifestaciones; y en reuniones de activistas organizadas al interior de Facultades que se mantenían ocupadas.

\begin{tabular}{|c|c|c|}
\hline Año & $\begin{array}{c}\text { Eventos de protesta estudiantil } \\
\text { en Concepción }\end{array}$ & $\begin{array}{c}\text { Participación directa del } \\
\text { equipo en eventos de protesta } \\
\text { callejera }\end{array}$ \\
\hline 2011 & 37 & 20 \\
\hline 2012 & 13 & 7 \\
\hline 2013 & 9 & 4 \\
\hline 2014 & 14 & 10 \\
\hline
\end{tabular}

Fuente: elaboración propia.

Simultáneamente desarrollamos entrevistas etnográficas con activistas del movimiento; registro fotográfico y audiovisual de las manifestaciones callejeras. Adicionalmente implementamos, durante el año 2013 y 2014, la producción de mapeos colectivos y participativos (Iconoclasistas, 2013) con activistas, sobre las rutas y repertorios de acción colectiva ligados a lo que aquí llamamos el artivismo urbano juvenil, preferentemente centrados en el año 2011. Estos mapas fueron generados y validados en conjunto con diversos activistas y protagonistas de las acciones callejeras que aquí se describen. Lo que a continuación presentamos constituyen fragmentos del relato etnográfico que describe los principales repertorios de acción colectiva callejera vinculado a lo que aquí denominamos artivismo. Junto con ello incorporamos algunas imágenes de los eventos y también uno de los mapas que co-elaborados en este contexto. 


\section{HALLAZGOS: CARTOGRAFÍAS DEL ARTIVISMO URBANO JUVENIL}

Durantelos meses de mayo a diciembre del año 2011 y más intermitentemente los años 2012, 2013, 2014 y 2015; diversos espacios de la ciudad de Concepción se fueron dibujando -durante las convocatorias a marcha y protesta estudiantil- de múltiples tonalidades y cuerpos manifestantes que coreográficamente diseñaban otros modos de utilizar las calles y las avenidas del centro de la ciudad ${ }^{5}$. Es decir, otro "orden público"; uno que no se administraba centralizadamente por la autoridad política oficial o desde quienes tenían la supuesta misión de "custodiarlo": las fuerzas policiales. A partir de nuestro trabajo de campo, junto a los tradicionales repertorios de protesta social callejera, fuimos identificando y distinguiendo cuatro tipos emergentes de repertorios de protesta callejera ${ }^{6}$ ligado a lo que aquí llamamos el artivismo urbano juvenil: [1] las acciones de arte; [2] prácticas de carnaval; [3] cuerpos performáticos; [4] encuentros efímero-masivos.

\section{ACCIONES DE ARTE CALLEJERO (HABLAN POR SÍ MISMAS SIN EXPLICACIÓN)}

Por repertorios de protesta callejera vinculados con las acciones de arte consideramos para el caso de esta sección a las llamadas instalaciones urbanas y las intervenciones urbanas. Estas suelen ser de carácter fijo y permanecen por un tiempo acotado sobre un soporte urbano altamente expuesto al flujo de personas y la mirada de transeúntes. Interrumpiendo sutilmente el tráfago normalizado de la ciudad y su paisaje habitual. El contexto de la puesta en escena suele ser durante el trayecto de una marcha o durante un día ritual que conmemora algún acontecimiento, o bien, se utiliza para contestar mediante este formato a la autoridad oficial respecto de las medidas que toma frente a la contingencia.

\footnotetext{
${ }^{5}$ El año 2009 hubo un total de 1.773 manifestaciones callejeras en Chile; el año 2010 un total de 2.116, mientras que el año 2011 se dispara a una cifra no vista desde la época de la dictadura militar, con un total de 6.938 manifestaciones en el espacio público (PNUD, 2012). Durante el 2011, se organizaron movilizaciones regulares para exigir educación pública gratuita; se ocuparon más de 600 escuelas y 17 universidades en todo Chile. Más antecedentes sobre estos datos, consultar: PNUD, 2012; Arditi, 2012; Koschutzke, 2012; Figueroa, 2012.

${ }^{6} \mathrm{Y}$ que en su interior agrupan una amplia gama de tácticas en el espacio, como: el pueblo unido avanza sin partido, cuerpos formando la frase no + lucro, sátira terrorista, bloqueo con lanas en el edificio del Arco de la Universidad de Concepción, UdeC, semáforos humanos, acción muerte Manuel Gutiérrez, acción mi educación mi condena, besatón por la educación, choritos con limón, suicidio colectivo, maquinaria de guerra, rayado de cancha, la Moneda y los partidos políticos, marionetas gigantes, cuerpos de consumo, endeudatón, matrimonio por conveniencia, etc. Y que por razones de extensión sintetizamos solo en las que se describen a continuación.
} 
La Universidad de Concepción $n^{7}$ posee espacios que constituyen patrimonio de la ciudad de Concepción y de Chile. Uno de esos lugares emblemáticos lo conforma el Foro de la Universidad, un espacio al aire libre inscrito en el corazón del campus con estructura de anfiteatro, donde regularmente se realizan diversas actividades culturales; y que dado sus dimensiones, le permite congregar a un gran número de personas. Por lo mismo, durante las manifestaciones del año 2011 fue espacio de reunión e intervención urbana privilegiado por los jóvenes estudiantes y activistas del movimiento. Durante los eventos etnográficos de mayor convocatoria proliferaron las llamadas intervenciones urbanas e instalaciones artísticas de diverso linaje. El día 29 de septiembre temprano por la mañana se alcanzaban a observar consignas escritas con papeles blancos sobre los peldaños del Foro, muy probablemente con hojas de cuaderno estudiantil o tipo carta donde imprimen sus informes académicos, y donde se leía con enormes letras: "El pueblo unido avanza sin partidos". En otra oportunidad el mismo Foro era utilizado por los estudiantes para consignar: "No + Lucro". Durante otro evento etnográfico del año 2011 el edificio en forma de arco de la Facultad de Medicina apareció las primeras horas de la mañana completamente tejido con lana de color rojo a nivel del suelo. Una trama espesa bloqueaba su acceso impidiendo el desplazamiento y la circulación. Los transeúntes y la gente que a esa hora viajaba en transporte público por una de las principales avenidas de la ciudad miraban atónitos la "instalación" en el acceso más relevante que tiene la Universidad desde la ciudad a su campus. En el núcleo de esta muda y enorme red roja dispuesta en la superficie del suelo figuraba un enorme signo peso (\$), eclipsando el histórico símbolo del escudo de la Universidad dispuesto originalmente sobre la superficie de ese acceso. Durante junio del año 2016 se volvió a repetir la instalación en contexto de paro y movilización estudiantil. Toda una gramática visual y semiótica que apelaba a otro estado de cosas y que interrumpía la linealidad histórica oficial, introyectando en el orden perceptual y sensitivo normalizado de los transeúntes una demanda de un tiempo pasado que se actualizaba como ruptura. Un deseo de recuperar lo que en otro momento histórico el pueblo ganó y que en el actual contexto histórico se encontraba expropiado.

\footnotetext{
${ }^{7}$ La Universidad de Concepción y su campus, con $1.425 .900 \mathrm{~m}^{2}$, se diseñó urbanísticamente como un espacio público de la ciudad y en completa integración a las principales calles del centro, por cuanto no se encuentra ni amurallado ni de espaldas a la ciudad, todo lo contrario, en tanto espacio público es poroso a los tránsitos libres y sin discriminación explícita. Lo que constituye uno de sus principales valores desde el punto de vista urbano, pero también lo hace vulnerable al control y la invasión de fuerzas hostiles y muchas veces represivas. Las dinámicas de "producción del espacio" (Lefebvre, 2013) y re-creación constante del mismo, a partir de la "ocupación" de diversos edificios de la Universidad, ha permitido que históricamente el campus se presente como un territorio estratégico la colonización para los grupos de manifestantes.
} 
Destacamos también la intervención urbana que los estudiantes denominaron durante el año 2011 el "Rayado de cancha". Una acción móvil y de carácter itinerante puesta en práctica mientras la marcha avanzaba y seguía su trayectoria por las principales calles de Concepción. Y donde los estudiantes dibujaban con tiza sobre el pavimento de la calle una cancha de fútbol. Luego improvisaban arcos, armaban dos equipos pequeños y se ponían a patear un balón de fútbol. Si la marcha interrumpía el regular funcionamiento de la ciudad, esta acción era una interrupción dentro de otra interrupción mayor. La multitud de manifestantes se detenía en enjambres a observar el partido de fútbol y animaba a sus equipos. Hasta goles se hacían. Luego de un gol se desmontaba el artefacto y se proseguía con la marcha. Más adelante, en otra esquina, se replicaba la acción. La ciudad ahora era un "estadio"; los "partidos" se jugaban en la calle; y los estudiantes en este contexto eran los que "rayaban la cancha".

\section{PRÁCTICAS CARNAVALESCAS (FUNDEN LA MARCHA POLÍTICA TRADICIONAL CON LA FIESTA URBANA)}

Las prácticas carnavalescas incluyen un conjunto de acciones durante las marchas que recuperan elementos de la cultura popular para desafiar al poder y comunicar públicamente su malestar, desde luego sin socavar de modo directo las bases del sistema, pero generando -como las termitas- un proceso lento e irreversible de debilitamiento y deslegitimación de sus soportes. Dentro de estos repertorios en contexto de protesta urbana hemos observado una enorme gama, donde figuran la parodia, el sarcasmo, la burla, la escenificación de ritos mortuorios, la teatralización del incesto ente dinero y política, los disfraces, la música, el consumo de estimulantes, la danza, el erotismo y la diversidad sexual al ritmo de las batucadas. "Carnavales por la educación", como los mismos activistas los denominan. Lo que vendría a desdibujar -inicialmente- el tradicional y disciplinado "marchar" de los antiguos militantes, para decantar en una protesta urbana que deviene en carrete (o sea, fiesta callejera): antes, durante y después de haber marchado o participado en la movilización callejera. Muchas veces observamos que la furia se combinaba con el éxtasis colectivo. No es extraño en sociología hablar en estos contextos de ebullición o efervescencia socio-emocional, una experiencia religiosa, pues parece que algo se logra re-ligar de modo contingente y provisional.

Estos repertorios de acción colectiva en contexto de protesta callejera, ligados con las acciones de arte o dinámicas carnavalescas, no los recordamos de modo visible en la historia reciente de Chile, ni de modo masivo, ni en una escala nacional, ni están presentes de modo protagónico en la bibliografía que narra los acontecimientos y los enfrentamientos callejeros durante la dictadura militar, 
durante el plebiscito del año 1988 o durante la primera parte de la transición a la democracia ${ }^{8}$. Responden más bien a repertorios que emergen con fuerza y visibilidad después del año 2011, cuando la marcha reivindicativa o política comienza a confundirse con el carnaval urbano que mezcla una gama mucho más heterodoxa de prácticas y emociones. Nuevos repertorios de acción colectiva en contexto de protesta callejera (combustionados por los medios y las nuevas tecnologías de la comunicación a nivel global) que representan formas de innovación social para expresar desobediencia civil mediante la no-violencia-activa.

Recordamos aquí, en tanto repertorios de acción colectiva significativos, al carro alegórico que representaba al Palacio de Gobierno, la Moneda en la ciudad de Concepción durante el año 2011; donde se portaban los emblemas de los partidos políticos de gobierno y oposición. Luego al llegar la marcha a la Plaza Independencia de Concepción, se le prendió fuego al carro alegórico. También observamos en contexto de marcha durante el año 2011 y 2012 múltiples velorios, funerales y luto riguroso que vestían los activistas, pues la educación pública en nuestro país estaba muriendo. Marionetas gigantes con los rostros del expresidente Piñera y sus ministros que acompañaron muchos trayectos y jornadas de marcha, también fueron incendiadas en todas las oportunidades en que estuvimos presentes. Durante el año 2012 los estudiantes diseñaron y construyeron con material reciclado artefactos que simulaban jaulas o calabozos con barrotes, situándose por detrás de estos mientras se desplazaban por las calles en contexto de marcha. Junto a esa manifestación se alcanzaba a leer una consigna que señalaba: "Mi educación, mi condena". Otra de las acciones que recuerdan los y las entrevistadas durante el año 2012 y el año 2013 son los modelos a escala del Guanaco y el Zorrillo9. La elaboración de estos carros alegóricos implicaba tiempo y planificación para los grupos de activistas, un proceso de diseño y producción importante antes de la puesta en escena el día de la marcha, y que siempre se organizaba y montaba en las instalaciones universitarias o

\footnotetext{
${ }^{8}$ Las referencias y antecedentes inevitables en ese contexto histórico de Chile, lo constituyen el CADA (Colectivo de Acciones de Arte) y Las Yeguas del Apocalipsis, con acciones mucho más localizadas geográficamente y espacialmente. Sobre estos aspectos consultar Nelly Richard, "La insubordinación de los signos: cambio politico, transformaciones culturales y poéticas de la crisis"; Editorial Cuarto Propio, Santiago de Chile, 1994. De la misma autora consultar. "Residuos y metáforas (ensayos de crítica cultural sobre el Chile de la transición)". Editorial Cuarto Propio, Santiago de Chile, 1998. Otra referencia inevitable -aunque con un nivel de parentesco menos directo- lo conforman las acciones de denuncia callejera realizadas por las agrupaciones de derechos humanos durante la dictadura chilena, donde destaca significativamente la del Movimiento Sebastián Acevedo Contra la Tortura. Para este último caso revisar del autor Hernán Vidal "El Movimiento Contra la Tortura. Sebastián Acevedo. Derechos Humanos y la producción de simbolos nacionales bajo el fascismo chileno". Santiago de Chile, Mosquito Editores, 2002.

${ }^{9}$ Ambos hacen referencia a los vehículos que utilizan las Fuerzas Especiales de Carabineros de Chile: el Guanaco es un carro lanza-aguas, mientras que el Zorrillo es un carro lanza gases.
} 
escuelas que se mantenían "ocupadas” y auto-gestionadas por estudiantes. Ya en la marcha los artefactos generados con material reciclado avanzaban -cual caparazónabriéndose paso por el río de manifestantes. Al interior de estos se observaba a través de sus ventanillas a sus tripulantes sosteniendo y haciendo avanzar el vehículo, avanzando entre la multitud y teatralizando su hostilidad con los manifestantes. El remate de la marcha en Plaza Perú, frente a las instalaciones de la Universidad de Concepción, consideraba incendiar el artefacto, cuyo material consumido por las llamas se convertía ritualmente en barricada en medio de la avenida.

Imposible no destacar, durante el crudo invierno del año 2011, las marchas nocturnas por las principales avenidas de las ciudades chilenas al ritmo de consignas y golpes de "cacerolas". O bien, la imborrable "marcha de los paraguas" el 14 de julio del año 2011 en Concepción y el 18 de agosto en Santiago. Marchamos por Concepción a pesar del frío y la persistencia de la lluvia. Los manifestantes eran estudiantes universitarios, secundarios, profesores, apoderados de colegios, niños y niñas, familias completas. Predominaban los paraguas negros que cubrían las cabezas como una cinta larga, estrecha y protectora que avanzaba lentamente para cubrir las principales avenidas de las grandes ciudades del país. Los paraguas se convirtieron en un artefacto colectivo, compartido por la multitud de cuerpos que avanzaban abigarrados por la columna aguantando el agua, el frío, el viento y el agotamiento después de cuatro meses de movilización nacional. Eso no impidió las múltiples expresiones de entusiasmo y euforia colectiva, lienzos, cánticos y la aparición de marionetas gigantes y grupos de manifestantes avanzando sobre zancos.

\section{CUERPOS PERFORMÁTICOS (CUERPO COMO SOPORTE EXPRESIVO PARA LA DENUNCIA EN CONTEXTO DE MOVILIZACIÓN URBANA)}

Dentro de las múltiples performances que observamos el año 2011 y 2012, destacamos aquellas realizadas utilizando cuerpos desnudos como lienzos. El 29 de julio del año 2011 participamos en una actividad que se denominó "Carnaval por la Educación” en pleno centro de la ciudad de Concepción y organizada por los activistas del movimiento. Esta vez las manifestantes fueron mujeres que envolvieron su cabeza y rostro con un lienzo blanco, dejando al descubierto únicamente sus ojos, mientras el resto de su cuerpo permanecía desnudo y cubierto con una pintura de color gris metálico. También se dejaban ver algunos dibujos, mapas y consignas sobre la capa gris de pintura, por ejemplo, "Cuerpos de Consumo". Estos cuerpos circulaban por el centro de la ciudad -como fluye también el patrón monetario entre nosotros y nuestras relaciones- generando mediante su recorrido una trama de lugares y espacios donde predomina el intercambio monetario: bancos, centros comerciales, colegios, farmacias, supermercados, entre otros. 
El asesinato del joven Manuel Gutiérrez de 16 años en Santiago, por parte de un miembro de la policía de Carabineros, durante la jornada de protesta nacional del día 25 de agosto del año 2011, generó que muchos estudiantes se manifestaran con fuerza y de diversas formas en contra de dicho crimen. Durante los días siguientes a dicho incidente, en Concepción se realizó una marcha para repudiar el asesinato, la brutal represión y la criminalización del movimiento por parte del gobierno. Al finalizar la marcha frente a la Pinacoteca de la Universidad dos activistas mujeres se desnudan y se vacían pintura roja sobre sus cuerpos. Luego caminan en silencio entre la multitud de manifestantes y se dirigen hacia el interior de una de las Facultades de la Universidad.

\section{ENCUENTROS EFÍMERO-MASIVOS (CONGREGAN POR UN TIEMPO BREVE UN ENJAMBRE DE ACTIVISTAS ANÓNIMOS EN UN ESPACIO PÚBLICO DE LA CIUDAD PARA REALIZAR UNA ACCIÓN ÚNICA Y LUEGO SE DISUELVEN FUGAZMENTE)}

Suicidios colectivos, danza de los estudiantes-zombies (el thriller de la educación mercantilizada), besatón por la educación, etc. fueron algunos de los encuentros que aquí llamamos efímero-masivos ${ }^{10}$ y que observamos durante los ańos 2011, 2012 y 2013 en la ciudad de Concepción. De acuerdo a nuestro trabajo de campo, podemos señalar que son encuentros convocados por activistas a través de redes sociales como Facebook, y que reúnen a un conjunto de personas cuyo objetivo puntual es ocupar un espacio público emblemático de la ciudad transformándolo de manera súbita y fugaz en un teatro o escenario para comunicar ciertos contenidos vinculados con las demandas del movimiento estudiantil.

Estos eventos son filmados y luego difundidos en las redes sociales, mezclando una reivindicación política con una acción lúdica y de diversión. Lo que generó en la prensa y la ciudadanía mucha empatía con la imagen del movimiento, y compromiso socio-emocional con las demandas de los activistas. Así, el día 05 de julio del año 2011 a las 15:30 horas comenzó a llegar a la Plaza de Tribunales del centro de Concepción un grupo de estudiantes universitarios y secundarios. Cerca de las 16:00 horas sumaban un número cercano a los 100 manifestantes que se dispusieron en parejas -homo y heterosexuales- y comenzaron a besarse ininterrumpidamente por

\footnotetext{
${ }^{10}$ Aquí preferimos designarlos así para distinguirlos del flashmob (multitud relámpago), pues siendo parientes cercanos, el flashmob ha venido decantando en el último tiempo hacia actividades más comerciales que reivindicativas o micro-políticas. De todas formas, el flashmob es una acción que tiene su origen en el marketing, pero que ha sido re-apropiada por diversos movimientos sociales, otorgándoles un componente más político o reivindicativo.
} 
largos minutos frente a la mirada atónita de los transeúntes. Sobre las espaldas de muchas parejas se observaron pancartas alusivas al "No + Lucro en Educación". Cerca de las 16:30 horas. los activistas se dispersaron del lugar.

\section{MAPA 1: Caleidoscópolis}

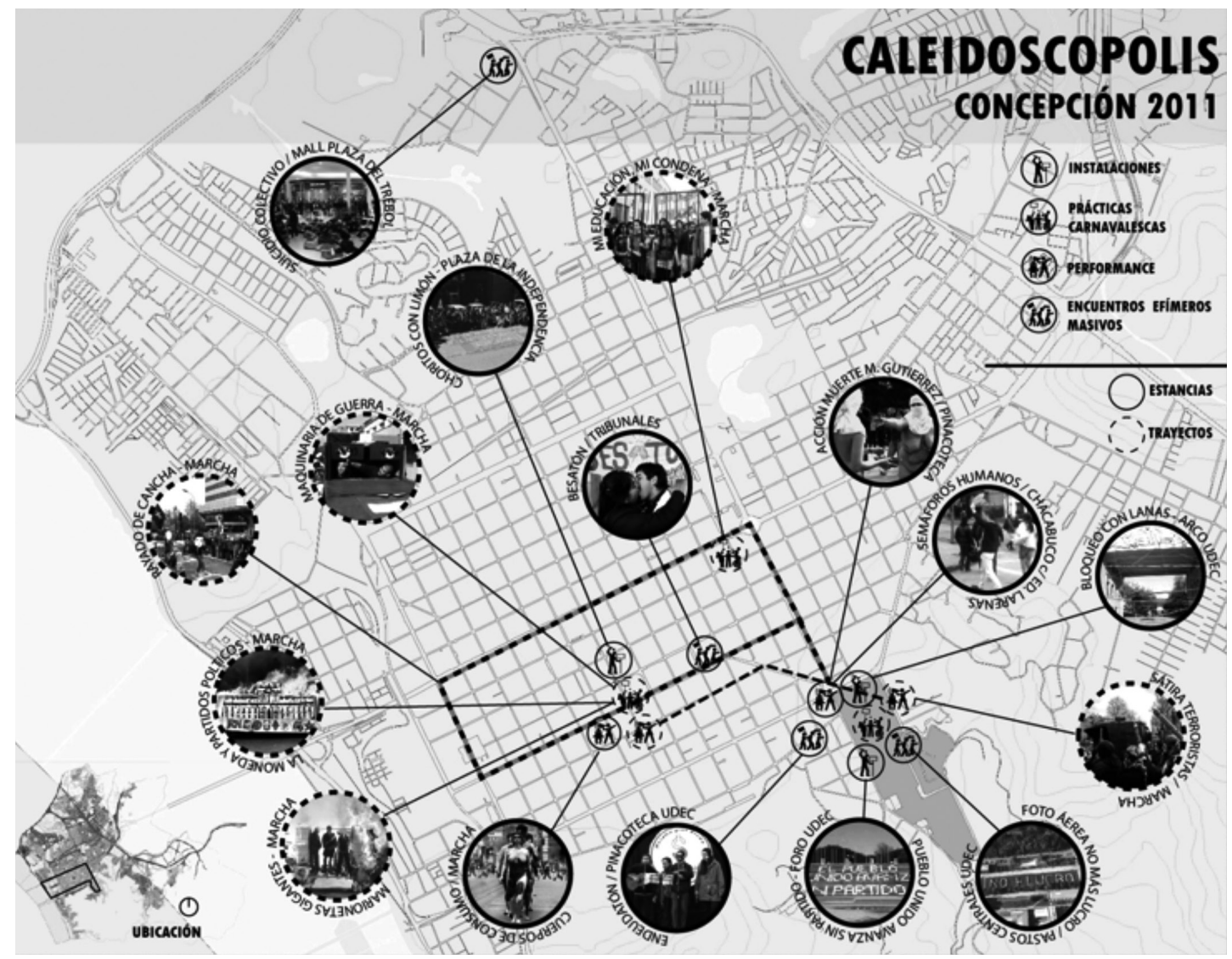

Fuente: elaboración propia.

\section{CONCLUSIONES Y DISCUSIONES}

Esta concepción lúdica y policromática de la desobediencia civil, es frivolizada y banalizada tanto por la visión política más canónica (la política de partidos y de movimientos sociales tradicionales), como por la visión académicointelectual más convencional; así como por el establisment en general. El reclamo o la displicencia contra este tipo de manifestaciones que aquí llamamos artivistas, generalmente se refiere a que son manifestaciones esteticistas, vanguardistas y hedonistas, que rápidamente son rentabilizadas o comercializadas por los medios; y que su impacto político sería menor, pues carecen de un plan o propuesta de 
transformación más estructural o subversiva con el orden dominante (Delgado, 2013; Valdivieso, 2014; Cadenas, 2015). Parafraseando a Delgado (2013), la protesta callejera de antańo se habría visto superada y subsumida por un nuevo estilo de arte político que tiene a la fiesta (o el carnaval) por matriz cultural, donde se con-funde la protesta callejera tradicional con géneros artísticos actuales como el performance o las instalaciones urbanas; privilegiando objetivos más expresivos que subversivos. Pero lo que aquí planteamos es que nos hemos encontrado con otro tipo de combates y guerrillas urbanas (preferentemente a partir del año 2011 en Chile, y a nivel global también), que no excluye los repertorios clásicos de protesta urbana, pero que se combinan con repertorios emergentes de protesta urbana, más centrados en aspectos comunicacionales, socio-afectivos, estéticos y lúdico-visuales; sin que por ello se vea afectado el rendimiento antagónico la ciudadanía por acumulación histórica de largo plazo.

Efectivamente las prácticas de artivismo carecen de plan o de un programa político específico, son más tácticas que estratégicas, de modo que su diseño de futuro está más abierto que clausurado por etapas o axiomas muy deterministas y militantes. No hay plan, pues las propias prácticas divergentes en el espacio son el plan (Arditi, 2012; Castells, 2012). Tienen un potencial más instituyente, donde el plan lo constituyen sus formas de actuar acumulativas para producir un acontecimiento desestabilizador, acaso portales por donde se filtra un tiempo porvenir (Arditi, 2012). Aquí la palabra también va perdiendo centralidad en tanto código hegemónico del decir y del comunicar, dando paso a lo inter-corporal como soporte expresivo y comunicacional privilegiado de la calle (Urzúa, 2015). Tampoco hay un sujeto romántico ni mesiánico contenido en el artivismo, ya que empíricamente conforman divergencias colectivas des-sujetadas, lo que no implica desconocer sus anclajes generacionales, de clase o de género, pero se asumen como disputas transversales y móviles en el espacio social. Así, no podemos hablar de objetivos para la construcción de un bloque histórico, pero sí de propósitos para fortalecer el espacio público como escena programática y dramática para la expresión de la ciudadanía, su malestar y su desobediencia con las formas predominantes de gestionar y privatizar la vida colectiva en el Chile tardo-pinochetista.

Siguiendo a Arendt (2005), la ciudad (polis) se presenta como el escenario privilegiado donde la gente se organiza para actuar y hablar juntos; se trata del espacio donde uno "aparece" ante otros y otros "aparecen" ante uno, es decir, donde los actores hacen su "aparición" de modo evidente y manifiesto, como es el caso de las prácticas vinculadas con el artivismo urbano juvenil, que contribuyeron durante el 2011 a hacer "aparecer" un mal-estar colectivo, generando un efecto que aquí llamamos de Caleidoscópolis.

Resulta pertinente entonces comprender - preliminarmente- al artivismo urbano juvenil, como repertorios de acción colectiva innovadores utilizados por el 
movimiento estudiantil chileno a partir del año 2011. Y que se inscriben dentro del campo de acciones vinculadas con el concepto de desobediencia civil (Arendt, 1999), pues responden a dos de sus rasgos centrales: (a) no fueron simples infracciones individuales y fragmentarias a la ley o el orden público imperante (delitos comunes como se les trató de hacer "aparecer" por el gobierno y criminalizar por ciertos medios), sino que acciones masivas y de alta convocatoria civil, sin la obtención de ventajas personales. Y (b) no implicaron un desacato encubierto o solapado (como suelen ser los actos delictuales), sino que se realizaron de cara a la vigilancia y el control policial callejero; y directamente en contra de la autoridad de gobierno. Lo que implicó un elemento de publicidad, es decir, hacer "aparecer" estas acciones en un lugar público y de alta circulación de transeúntes. Registrarla con recursos audiovisuales y luego difundirla por los medios y las redes sociales, erosionando y desautorizando la imagen del gobierno frente a la ciudanía y la opinión pública (nacional e internacional). Esto último, se hacía más patente cuando la policía entraba a reprimir públicamente acciones no-violentas del movimiento estudiantil.

Por todo lo expuesto hasta aquí, planteamos que la desobediencia civil también implicó obediencia civil dentro del movimiento, es decir, disciplina, organización colectiva, diseño de eventos, planificación, objetivos, coordinación, división de tareas, puesta en escena, evaluación y desafíos futuros, etc. Por lo cual el artivismo urbano juvenil constituye un arma que no se sustenta pura y simplemente en actos frívolos o hedonistas, ya que es parte del repertorio de una memoria generacional que no tiene su origen en el episodio del ańo 2011, sino que enlaza -de modo denso e intergeneracional- con otros hitos históricos del Chile reciente ${ }^{11}$. Donde confluyen de manera paradigmática: lo político, el espacio urbano, la estética y el componente socio-emocional para el despliegue de la acción colectiva. Y si se trata de efectividad, sostenemos que enfrentar la represión policial en la calle y en otros espacios sociales con los mismos medios que esta, no solo es poco estratégico (dado el monopolio de la violencia física del Estado), sino que refuerza y legitima las bases de sustentación de cualquier régimen opresivo. Lo que da cuenta que estas luchas "termitas" han sido muy efectivas en la construcción histórica de aprendizajes (Salazar, 2002) y sentidos compartidos por estos jóvenes, desplegando una nueva capacidad de agencia (Urteaga, 2011), una subjetivación política (Rancière, 2007) de carácter generacional, que logró poner en evidencia, con recursos cotidianos de movilización socio-emocional en el espacio público, una profunda crisis de autoridad y legitimidad (hegemonía) por parte del gobierno ${ }^{12}$,

\footnotetext{
${ }^{11}$ Para mayor profundización, ver Muñoz (2012).

${ }^{12}$ Consultar Encuestas Adimark (2011). El nivel mínimo de aprobación alcanzado por Sebastián Piñera se produce en agosto de 2011 , con un $27 \%$ de aprobación y un $62 \%$ de desaprobación a la gestión gubernamental.
} 
la política oficial y su propio mecanismo de representación institucional. Pero no solo eso, sino que también logró proponer y poner en juego renovadas formas de elaboración y expresión de la conflictividad social, donde la política se vivió como arte y el arte como política (Botero y Muñoz, 2011), inyectando en el horizonte cotidiano de la ciudadanía la posibilidad de un modelo de democracia radical (Mouffe, 1999), donde lo político no se agota en el cálculo procedimental, la gestión de los expertos o la demanda sectorial de un actor coyuntural. Aquí la política no estaría restringida únicamente a la gestión de gobierno, sino a las prácticas que interrumpen dicho proceso, a la parte de los que no cuentan, a la parte de los sin-parte y donde se instituye y visibiliza un lugar que antes no existía y no poseía fisonomía al interior de un campo de fuerzas determinado (Rancière, 2007). Puesto así, toda protesta es instrumentalmente ineficiente, pero siempre pone en juego un excedente, un plus-valor simbólico, imaginario y socio-emocional que no estaba previsto y codificado en su despliegue original (Aimar, 2012). Con todo, estamos asistiendo a un ciclo largo, complejo y caleidoscópico de movilizaciones sociales, en ese contexto no podemos calificar de fracaso los intentos generacionales por cambiar la herencia del Chile tardo-pinochetista, no se trata de años pedidos, todo lo contrario, las ciudadanías no solo han internalizado de modo profundo el malestar con el consenso neoliberal, con una democracia donde no se juega nada, ninguna decisión que pueda cambiar sustantivamente la vida de las mayorías postergadas; sino que - por sobre todo- las ciudadanías se han constituido como tales mediante el despliegue de su propio protagonismo impugnatorio en el largo plazo; a través de la apropiación cotidiana de diversos espacios sociales donde han ido derrocando dictaduras, construyendo colaborativamente una vida más justa y democratizando de modo cotidiano, autónomo y participativo a la propia democracia.

¿Por qué existe la creencia generalizada de que los movimientos han desaparecido, de que los últimos cuarenta años han sido un período en el que no ha ocurrido nada? Tal vez se deba a que estamos demasiado acostumbrados a la historia como historia política. Y sin embargo, por encima de todo, la historia es social y cultural. Es la historia de la vida diaria de los hombres y mujeres. Si se observa de cerca, esta historia revelará cambios decisivos que incluyen una revolución social (Heller, 1988, p. 49). 


\section{REFERENCIAS}

Adimark. Estudios-2011. Disponible en: http://www.adimark.cl/es/estudios/ archivo.asp?prd=2011\&tip=1 [Consultado el 17 de marzo de 2015].

Aguilera, Óscar. Generaciones: movimientos juveniles, politicas de la identidady disputas por la visibilidad en el Chile neoliberal. Buenos Aires: CLACSO, 2014.

Aimar, Lucas. "Prácticas intersticiales y acción colectiva: algunas lecturas sobre lo festivo en contextos de protesta social”. En Scribano, Adrián; Magallanes, Graciela y Boito, María Eugenia. (Comp.). La fiesta y la vida: un estudio desde una sociología de las prácticas intersticiales. Buenos Aires: Editorial Ciccus, (2012): 163-182.

Arendt, Hannah. La condición humana. Buenos Aires: Paidós, 2005.

Arendt, Hannah. La crisis de la república. Buenos Aires: Taurus, 1999.

Arditi, Benjamín. "Las insurgencias no tienen un plan - ellas son el plan: Performativos políticos y mediadores evanescentes", Revista Sul-Americana de Ciencia Politica, 1/2 (2012): 1-18.

Auyero, Javier. "La geografía de la protesta". Trabajo y Sociedad. Indagaciones sobre el empleo, la cultura y las prácticas políticas en sociedades segmentadas III/4 (2002).

Balardini, Sergio. “¿Qué hay de nuevo, viejo? Una mirada sobre los cambios en la participación política juvenil”, Nueva Sociedad, 200 (2005): 96-107.

Bonvillani, Andrea. "Cuerpos en marcha. Emocionalidad política en las formas festivas de protesta juvenil”, Nómadas, 39 (2013): 91-103.

Borges, Antonádia. Tempo de Brasilia. Río de Janeiro: Relume-Dumara, 2003.

Borja, Jordi y Muxí, Zaida. El espacio público: ciudad y ciudadanía. Madrid: Alianza, 2003.

Botero, Patricia y Muñoz, Erika. "Militancias estéticas y contra-comunicativas". En Boito, María Eugenia, Toro, Eliana y Grosso, José Luis (Comp.). Transformación social, memoria colectiva y cultura(s) popular(es). Buenos Aires: Estudios Sociológicos Editora, (2011): 399-411. 
Cadenas, Maribel. "El urbanismo del mientras tanto. Primeras notas etnográficas sobre prácticas de construcción colaborativa en tiempos de crisis". En Aricó, Giuseppe (Ed.). Mierda de Ciudad. Una rearticulación critica del urbanismo neoliberal desde las ciencias sociales. Barcelona: Ediciones Pollen, (2015): 167-183.

Castells, Manuel. Redes de indignación y esperanza: los movimientos sociales en la era de Internet. Madrid: Alianza, 2012.

Delgado, Manuel. “Artivismo y pospolítica. Sobre la estatización de las luchas sociales en contextos urbanos", Quaderns-e, 18 (2013): 68-80.

Feixa, Carles. "GeneraciónXX. Teorías sobrela juventud en la época contemporánea”, Revista Latinoamericana de Ciencias Sociales, Niñez y Juventud, 4/2 (2006).

Fernández, Ana. Las lógicas colectivas. Imaginarios, cuerpos y multiplicidades. Buenos Aires: Biblos, 2007.

Fernández, Roberto. "El espacio público en disputa: manifestaciones, ciudad y ciudadanía en el Chile actual", Revista Psicopersectivas. Individuo y sociedad, 12/2 (2013): 28-37.

Figueroa, Francisco. Llegamos para quedarnos. Crónicas de la revuelta estudiantil. Santiago de Chile: LOM, 2012.

Foucault, Michel. Microfísica del poder. Madrid: La Piqueta, 1992.

Garcés, Mario. El despertar de la sociedad. Los movimientos sociales en América Latina y Chile. Santiago de Chile: LOM, 2012.

Ganter, Rodrigo. "Consumos culturales juveniles: apuntes y pistas para posibles líneas de investigación en el Chile actual”. En Cottet, Pablo (Ed.). Juventudes. Metáforas del Chile Contemporáneo. Santiago de Chile: RIL editores (2015): 185 - 218.

Ganter, Rodrigo y Zarzuri, Raúl. "Metamorfosis de lo político-cultural y colectivos urbano-juveniles emergentes”. En Sepúlveda, Mauricio; Bravo, Carlos y Aguilera, Óscar (Comp.). Nuevas geografías juveniles. Santiago de Chile: Ediciones Universidad Diego Portales, 2005. 
González, Yanko. "Sumar y no ser sumados: culturas juveniles revolucionarias. Mayo de 1968 y diversificación identitaria en Chile”, ALPHA, 30 (2010): 111-128.

Guber, Rosana. La etnografía, método, campo y reflexividad. Bogotá: Grupo Editorial Norma, 2001.

Heller, Agnes. "Los movimientos culturales como vehículo de cambio", Nueva sociedad, No 96, 1988.

Hopenhayn, Martín. La juventud en Iberoamérica. Tendencias y urgencias. Santiago de Chile: CEPAL, 2004.

Iconoclasistas. Manual de mapeo colectivo: recursos cartográficos críticos para procesos territoriales de creación colaborativa. Buenos Aires: Tinta de Limón, 2013.

Juris, Jeffrey, Pereira, Inés y Feixa, Carles. "La globalización alternativa y los 'novísimos' movimientos sociales", Revista del Centro de Investigación Universidad La Salle 10/37 (2012): 23 -39.

Koschutzke, Alberto. "Chile frente a sí mismo. Los límites del fundamentalismo de mercado y las protestas estudiantiles", Nueva Sociedad, 237 (2012):17- 31.

Krauskopf, Dina. "La condición juvenil contemporánea en la constitución identitaria", Última Década, 33 (2010): 27- 42.

Le Breton, David. La sociología del cuerpo. Buenos Aires: Nueva Visión, 2011.

Lefebvre, Henri. La producción del espacio. Madrid: Capitán Swing, 2013.

Mannheim, Karl. Diagnóstico de nuestro tiempo. Ciudad de México: Fondo de Cultura Económica, 2005 [1944].

Massey, Doreen. Space, Place and Gender. Minneapolis: University of Minnesota Press, 1994.

Mayol, Alberto. No al lucro. De la crisis del modelo a la nueva era politica. Santiago de Chile: Editorial Debate, 2012.

Mead, Margaret. Cultura y Compromiso. Barcelona, Gedisa, 2009. 
Melucci, Alberto. Challenging codes: collective action in the information age. Cambridge, Cambridge University Press, 1996.

Mouffe, Chantal. El retorno de lo politico. Comunidad, ciudadania, pluralismo, democracia radical. Barcelona: Paidós, 1999.

Mouffe, Chantal. "Política y pasiones: Las apuestas de la democracia". En Arfuch, Leonardo (Ed.). Pensar este tiempo. Espacios, afectos, pertinencias. Buenos Aires: Paidós, (2005): 75 - 97.

Muñoz, Víctor. Generaciones. Juventud universitaria e izquierdas politicas en Chile y México (Universidad de Chile - UNAM 1984 - 2006). Santiago de Chile: LOM, 2012.

Muñoz, Víctor. "Juventud y Política en Chile. Hacia un enfoque generacional”, Última Década, 35 (2011): 113-141.

Natanson, José. "El retorno de la juventud. Movimientos de repolitización juvenil en nuevos contextos urbanos", Nueva sociedad, 243 (2013).

Náteras, Alfredo. "Trayectos y desplazamientos de la condición juvenil contemporánea”, El cotidiano, 20/126 (2004): 206 -213.

Observatorio de los derechos de la juventud (ODJ). Ser joven. Perspectiva de Derecho. Disponible en: http://ojoambulante.org.mx/pdf/serjoven.pdf [Consultado el 16 de diciembre de 2014].

Opazo, Daniel. "Espacio transitorio. Producción, prácticas y representaciones del espacio público político en Santiago de Chile: 1983 - 2008”. Tesis Doctoral. Santiago de Chile, Pontificia Universidad Católica de Chile, 2009.

Oslender, Ulrich. "Espacio, lugar y movimientos sociales: hacia una "espacialidad de resistencia”", Scripta Nova. Revista electrónica de geografía y ciencias sociales VI/115 (2002).

Pile, Steve. "Introduction. Opposition, political identities and spaces of resistance". Geographies of Resistance. Pile, Steve y Keith, Michael (Ed.). Londres: Routledge (1997): 1- 32.

PNUD. Bienestar subjetivo: el desafio de repensar el desarrollo. Santiago de Chile: PNUD, 2012. 
Rancière, Jacques. El desacuerdo. Politica y filosofía. Buenos Aires: Nueva Visión, 2007.

Reguillo, Rossana. La construcción simbólica de la ciudad. Sociedad, desastre, comunicación. Guadalajara: ITESO/Universidad Iberoamericana, 2005.

Reguillo, Rossana. Emergencia de Culturas Juveniles. Estrategias del Desencanto. Bogotá: Norma, 2000.

Richard, Nelly. La insubordinación de los signos: (cambio politico, transformaciones culturales y poéticas de la crisis. Santiago de Chile: Editorial Cuarto Propio, 1994.

Richard, Nelly. Residuos y metáforas (ensayos de critica cultural sobre el Chile de la transición. Santiago de Chile: Editorial Cuarto Propio, 1998.

Ruiz, Carlos. Conflicto social en el "neoliberalismo avanzado". Análisis de clase de la revuelta estudiantil en Chile. Buenos Aires: CLACSO, 2013.

Salazar, Gabriel y Pinto, Julio. Historia contemporánea de Chile, Tomo V. Niñez y Juventud. Santiago de Chile: LOM, 2002.

Salcedo, Rodrigo. "El espacio público en el debate actual: Una reflexión crítica sobre el urbanismo post-moderno", Eure, 28/84 (2002): 5-19.

Sandoval, Mario. "Jóvenes y valores: reflexiones sociológicas a partir de los datos empíricos". En Cottet, Pablo (Ed.). Juventudes. Metáforas del Chile Contemporáneo. Santiago de Chile: RIL editores (2015): 253 -278.

Scribano, Adrián, Magallanes, Graciela y Boito, María Eugenia. La fiesta y la vida: un estudio desde una sociología de las prácticas intersticiales. Buenos Aires: Editorial Ciccus, 2012.

Segovia, Carolina y Gamboa, Ricardo. "Chile: el año en que salimos a la calle”, Revista de Ciencia Política, 32/1 (2012): 65-85.

Seoane, Viviana. "Jóvenes, riesgos y desafiliaciones en Latinoamérica. Entrevista a Rossana Reguillo Cruz", Propuesta Educativa, 28 (2007): 51-57.

Serna, Leslie. "Globalización y participación juvenil. En búsqueda de elementos para la reflexión”, Jóvenes, Reviste de estudios sobre juventud, 2/5 (1998). 
Soja, Edward. Postmodern Geographies. The Reassertion of Space in Critical Social Theory. Londres, Verso, 1989.

Tarrow, Sidney. El poder en movimiento. Los movimientos sociales, la acción colectiva y la politica. Madrid: Alianza Editorial, 2004.

Toussain, Eric. "La indignación mundial y su marco internacional". Fernández, Joseba (Ed.). Ocupemos el mundo. Barcelona: Editorial Icaria, (2012): 27-40.

Traugott, Mark. Protesta social. Repertorios y ciclos de acción colectiva. Barcelona: Hacer, 2002.

Urteaga, Maritza. La construcción juvenil de la realidad. Jóvenes mexicanos contemporáneos. Iztapalapa: Universidad Autónoma Metropolitana, 2011.

Urzúa, Sergio. “¿Cómo marchan los jóvenes en el Chile de postdictadura? Algunas notas acerca de la apropiación del espacio público y el uso del cuerpo", Revista Última Década, 42 (2015): 39-64.

Valdivieso, Mercedes. "La apropiación simbólica del espacio público a través del artivismo. Las movilizaciones en defensa de la sanidad pública en Madrid”. Revista Scripta Nova, Vol XVIII, no 493 (11), Barcelona. Noviembre de 2014. Disponible en www.ub.edu/geocrit//sn/sn-493/493-11.pdf [Consultado el 20 de enero de 2015].

Valenzuela, Esteban y Basaure, Lia. "Acciones colectivas territoriales en Chile, 2011-2013: de lo ambiental-reivindicativo al autonomismo regionalista”, Revista EURE, 42/125, (2016): 225-250.

Vidal, Hernán. El Movimiento Contra la Tortura. Sebastián Acevedo. Derechos Humanos y la producción de simbolos nacionales bajo el fascismo chileno. Santiago de Chile: Mosquito Editores, 2002.

Wallerstein, Inmanuel. La lucha mundial de clases: la geografía de la protesta. La Jornada; 5 de junio 2012. Disponible en: http: www.jornada.unam.mx/2012/06/03/ opinion/026a1mun [Consultado el 04 de marzo del 2015].

Zarzuri, Raúl y Ganter, Rodrigo. Culturas juveniles, narrativas minoritarias y estéticas del descontento. Santiago de Chile: Editorial Universidad Católica Silva Henríquez, 2002.

Zibechi, Raúl. Genealogia de la revuelta. Argentina: una sociedad en movimiento. La Plata: Letra Libre, 2003. 